\title{
Impact of a summer extern program on nursing student's awareness of interprofessional collaboration and healthy, healing environments: A level II quasi-experimental design
}

\author{
Lisa A. Ruth-Sahd *1,2 \\ ${ }^{1}$ The Stabler Department of Nursing, York College of Pennsylvania, York, United States \\ ${ }^{2}$ Lancaster General Health Penn Medicine, Lancaster, United States
}

Received: April 18, 2016

DOI: $10.5430 /$ jnep.v6n12p63
Accepted: May 31, 2016

Online Published: July 25, 2016

URL: http://dx.doi.org/10.5430/jnep.v6n12p63

\begin{abstract}
Background: Student nurse externships bridge the gap between education and practice. These programs expose students to the interprofessional healthcare team, the work environment and its impact on themselves as well as their patients.

Methods: Research Objective/Questions: 1) What is the nurse externs' knowledge of a healthy healing environment (HHE) at the beginning of an 8 week summer externship program? 2) How does participation in the interprofessional externship inform the externs' knowledge and awareness of a HHE and 3) How does this knowledge affect the extern themselves and their patient outcomes? Design: A Level II Quasi-Experimental design was completed in 2013-2015 involving 3 cohorts each with 20 externs. Participants and Setting: A convenience sample of student nurses from baccalaureate and associate degree nursing programs who participated in a nursing externship. Methods: After informed consent, a survey of open-ended questions was administered at the beginning (week 1) and end (week 8) of the externship. Survey findings were compared using thematic content analysis.

Results: At the outset, externs demonstrated basic knowledge as to what a HHE means. By the end, externs were able to describe in depth a HHE for themselves and their patients. They also described their role on an interprofessional health care team when establishing and maintaining a HHE. Findings were 1) increased cognizance of a HHE (88\%); 2) enhanced mindfulness of working in a truly collaborative manner with the interprofessional healthcare team to improve decision-making (85\%); 3) broadened recognition how skilled communication among all interprofessional team members leads to a HHE (85\%); and 4) raised awareness of a HHE positively affecting their own health and improved outcomes in their patients (90\%).

Conclusions: The externs' perceptions of a HHE broadened over the course of the externship as did their understanding of their obligations in forming and maintaining a HHE. Externs also described the impact on patient outcomes.
\end{abstract}

Key Words: Nursing externship, Healthy healing environment, Interprofessional practice

\section{INTRODUCTION}

Teamwork and effective collaborative communication among healthcare providers are essential to creating healthy, healing environments (HHE) which promote nurse and patient safety and quality care. Who would ever believe that healthcare environments could be unhealthy places to work? Hospi-

\footnotetext{
* Correspondence: Lisa A. Ruth-Sahd; Email: lsahd@ycp.edu; Address: The Stabler Department of Nursing, York College of Pennsylvania, York, Pennsylvania, United States.
} 
tals are places patients go to get better and are supposed to be safe healthy environments for all. While much attention has focused on reducing needle sticks, the transmission of blood borne pathogens, back injuries and latex allergies, other injuries to healthcare providers result from psychological, social and spiritual interpersonal conflict.

Interpersonal conflict resulting from lack of support, lack of, or poor communication among healthcare team members, role conflict, role overload, work place stress, role confusion, ineffective leadership and management are prevalent in many healthcare settings. This dysfunctional culture has been reported by $95 \%$ of nurses ${ }^{[1,2]}$ and $100 \%$ of medical students. ${ }^{[3]}$ This impacts nursing recruitment, job satisfaction, retention, costs of healthcare and patient outcomes. ${ }^{[4-6]}$ The Institute of Medicine ${ }^{[7,8]}$ in their report to Err is Human: Building a Safer Healthcare System highlights the importance of creating an environment where there is open, trusting and collegial communication to improve the healthcare system and prevent errors.

It is imperative for undergraduate nursing curricula to incorporate HHE information early on in the curriculum, and not just in leadership courses. By doing this student nurses will begin their first clinical course with this information so they may establish methods with which they can assess the environment, mold their own practice, and improve their provision of healthcare with this content at the forefront of their mind. Students should be taught what a HHE is, barriers, challenges, risks and nursing roles in establishing a HHE for the benefit of their own health as well as that of their healthcare team and their patients. In addition, students must recognize how interprofessional collaboration fosters the development of a HHE. Externships create a perfect opportunity to reinforce nursing school curriculum, and they provide a longer period of engagement in the clinical learning environment thereby allowing students to practice in the trenches and become aware of the impact of interprofessional collaboration.

\section{Literature review}

Using KEY WORDS: Extern, externships, collaboration, safe practice, work environment, and interprofessional approach a comprehensive search of MEDLINE, CINAHL, ProQuest, Psych INFO and the Cochrane databases was conducted. A summary of the evidence (within last 10 years) confirms extern programs bridge the gap between education and practice by immersing students in the day to day responsibilities and obligations of the professional nurse, ${ }^{[9-11]}$ increase knowledge, and self-confidence ${ }^{[11,12]}$ provide clarity for specialty areas of nursing including perioperative, ${ }^{[13]}$ geriatrics ${ }^{[10,14]}$ and promote an awareness of cultural aspects of care. ${ }^{[15]}$

Interprofessional collaboration (IPC) is a key component to HHEs which, when done well supports retention ${ }^{[16-21]}$ and promotes quality care. ${ }^{[22,23]}$ The $\mathrm{WHO}^{[24]}$ defines IPC as "multiple health workers from different professional backgrounds provide comprehensive services by working with patients, their families, and communities to deliver the highest quality of care across settings". ${ }^{[24]}$ The NLN ${ }^{[25]}$ stated, "there is a growing need for interprofessional education for collaborative practice" (p.5). Among new graduate nurses, awareness of interprofessional collaboration eases the transition, reduces stress and improves retention. ${ }^{[21]}$

There is little evidence in undergraduate curricular assessments as to what content is covered regarding collaborative culture, or how to promote a $\mathrm{HHE}^{[26-30]}$ despite the ANA ${ }^{[31]}$ suggesting that, "all RNs and employers in all settings, including practice, academia, and research, must collaborate to create a culture of respect" (p.1). Ranjbar ${ }^{[32]}$ states this is an "ignored challenge in clinical nursing education". While increased attention has been paid over the years to HHE in practice $^{[33]}$ and effects on patient care,${ }^{[34,35]}$ very few have looked at what is covered as far as content in nursing education. ${ }^{[1,36]}$ Collins et al. ${ }^{[37]}$ suggests a capstone course integrating HHE standards into undergraduate curricula and emphasizes this is crucial for students to learn these standards before entering the workforce. By educating students regarding stress management and how to create a HHE they will have the necessary capabilities to deal with stress in their clinical education, and meet their educational goals. This adds to their professional competence so they may provide better health care in the future. ${ }^{[38]}$

\section{Theoretical framework}

The theoretical framework guiding this research is the American Association of Critical-Care Nurses ${ }^{[34]}$ definition of a healthy work environment. This definition includes six key components of (1) skilled communication, (2) true collaboration, (3) effective decision-making, (4) appropriate staffing levels, (5) meaningful recognition, and (6) authentic leadership. Likewise, the American Organization of Nurse Executives developed eleven categories for a HHE and includes: (1) patient care delivery and workplace design, (2) Magnet designation, (3) collaborative decision-making, (4) performance measurement and strategic planning, (5) leadership support and collegial communication, (6) leadership development and management culture, (7) professional support and development, (8) recognition of staff accomplishments, (9) benefits and compensation, (10) flexible scheduling, and (11) nursing wellness. To date, no studies have been conducted to identify what students know regarding HHEs, or how they 
may make positive changes for themselves and their interprofessional team to establish and maintain a HHE and identify how it impacts their nursing care.

Furthermore the neuropsychoimmunology scientific premise highlighting the integral relationship between the brain and how it interprets stressors and stressful environments and the body's immunological response is critically foundational to the necessity of including this information in the education of nurses. Healthcare environments may promote healing or exacerbate sickness for patients, significant others and as well as providers as they respond to the relationships, social support, and organizational culture.

\section{METHODS}

\subsection{Aims}

After this literature search was completed the following research questions were formulated: 1) What is the nurse externs' knowledge of a HHE at the beginning of an 8 week summer externship program? 2) How does participation in the interprofessional externship inform the externs' knowledge and awareness of a HHE and 3) How does this knowledge affect the extern themselves and their patient outcomes?

\subsection{Study design}

Using a Level II Quasi-Experimental design (externs = own control by examining the results of a pretest and post-test), demographic data as well as qualitative data was considered.

\subsection{Sample and data collection}

All 60 students participating in the nursing externship during the summers of 2013-2015 were included in this study. The externship followed guidelines for extern programs ${ }^{[39]}$ and was offered to student nurses within one year of graduating from an accredited program. A GPA of greater than 3.0 was required. The goals of this externship include:

- Increase clinical exposure to two acute care specialty areas in a Magnet hospital;

- Challenge externs to think critically while using a holistic perspective;

- Foster interprofessional collaborative relationships, socialization, and networking;

- Promote an awareness of the RN role on the interprofessional team;

- Expose externs to the fast-paced, specialized and technologically intensive clinical employment setting; and

- Introduce concepts of a HHE and orient externs to their role in developing and maintaining this environment.

The externs were informed of this optional study in a post clinical conference during the first week and were given the opportunity to participate. All externs agreed to participate and completed a survey week 1 including six open-ended questions (see Table 1) aimed at answering the first research question. In addition, a brief demographic survey (see Table 2) was completed. Week 8 , the same survey was administered with an additional question to address the second research question (see Table 1).

Table 1. SURVEY Questions (Same survey used week 1 and then again week 8 of the externship)

\begin{tabular}{|c|c|}
\hline 1) & $\begin{array}{l}\text { Please describe a healthy healing environment (HHE) and what it } \\
\text { means to you. }\end{array}$ \\
\hline 2) & Express your role as a student nurse extern in promoting a HHE. \\
\hline 3) & $\begin{array}{l}\text { How do you feel working in a HHE affects you as a nurse? Please be } \\
\text { specific as to how? }\end{array}$ \\
\hline 4) & $\begin{array}{l}\text { How do you feel working in a HHE affects your patient outcomes? } \\
\text { Please be specific as to how? }\end{array}$ \\
\hline 5) & Do you feel this externship promotes a HHE? If yes, how? If not, why? \\
\hline 6) & $\begin{array}{l}\text { What do you see as your role on an inter-professional health care team } \\
\text { in promoting a HHE? }\end{array}$ \\
\hline 7) & $\begin{array}{l}\text { QUESTION WEEK } 8 \text { only- Do you feel your participation in this } \\
\text { externship experience informed your perception of a HHE? If so, } \\
\text { how? Please be specific. }\end{array}$ \\
\hline
\end{tabular}

Table 2. Descriptive statistics of demographic variables (N $=60$ )

\begin{tabular}{|c|c|c|}
\hline & Frequency & Percentage \\
\hline \multicolumn{3}{|l|}{ Age } \\
\hline$<20$ & 8 & $13 \%$ \\
\hline $20-25$ & 40 & $67 \%$ \\
\hline$\geq 26$ Years & 12 & $20 \%$ \\
\hline \multicolumn{3}{|l|}{ Gender } \\
\hline Male & 8 & $13 \%$ \\
\hline Female & 52 & $87 \%$ \\
\hline \multicolumn{3}{|l|}{ Ethnic Groups } \\
\hline Caucasian & 51 & $85 \%$ \\
\hline Hispanic/Latino & 2 & $3 \%$ \\
\hline Black/African American & 2 & $3 \%$ \\
\hline Asian/Asian American & 2 & $3 \%$ \\
\hline Mixed Ethnicity & 3 & $5 \%$ \\
\hline \multicolumn{3}{|l|}{ Nursing Program } \\
\hline $\mathrm{ADN}$ & 39 & $65 \%$ \\
\hline BSN & 21 & $35 \%$ \\
\hline \multicolumn{3}{|l|}{ Nursing Level } \\
\hline December Graduates & 18 & $30 \%$ \\
\hline May Graduates & 44 & $70 \%$ \\
\hline \multicolumn{3}{|l|}{ Is this your first job? } \\
\hline $\begin{array}{l}\text { YES } \\
\text { NO If No, please briefly describe the job } \\
\text { responsibilities }\end{array}$ & $\begin{array}{l}20 \\
40\end{array}$ & $\begin{array}{l}33 \% \\
67 \%\end{array}$ \\
\hline \multicolumn{3}{|l|}{$\begin{array}{l}\text { Have you had previous experience in } \\
\text { acute care setting as a paid employee }\end{array}$} \\
\hline Yes & 15 & $25 \%$ \\
\hline No & 40 & $66 \%$ \\
\hline (5 externs did not answer this question) & 5 & $8 \%$ \\
\hline \multicolumn{3}{|l|}{$\begin{array}{l}\text { Have you had a class in school in which } \\
\text { work environment was discussed }\end{array}$} \\
\hline Yes & 12 & $20 \%$ \\
\hline No & 38 & $63 \%$ \\
\hline (10 externs did not remember) & 10 & $17 \%$ \\
\hline \multicolumn{3}{|l|}{$\begin{array}{l}\text { Have you had a leadership class in your } \\
\text { nursing education }\end{array}$} \\
\hline Yes & 40 & $67 \%$ \\
\hline No & 20 & $33 \%$ \\
\hline
\end{tabular}




\subsection{Ethical considerations}

Externs were informed both verbally and in writing and were assured complete confidentiality on the surveys. The verbal discussions in post clinical conference and informally throughout the externship appeared to be open and genuine. There were no grades associated with this externship so externs were free to share thoughts without consequences. The majority of the data were analyzed after the externship. The study protocol was approved by the institutional review board and was in compliance with ethical research regulations.

\subsection{Healthy healing environment post clinical confer- ence}

There was one structured post clinical conference for one hour, week 5 presenting evidence-based information regarding HHEs (see Table 3). The purpose was to educate externs on the complex, multifaceted nature of HHE and familiarize them with multiple theoretical perspectives. All externs attended however five were about 15-20 minutes late.

Table 3. Outline of Topics shared during post clinical conference on Healthy Healing Environments

I What is a Healthy Healing Environment to you?
a) Classroom
b) Clinical learning environment
c) Externship experience
II Components of a HHE defined by key nursing organizations
a) American Nurses Association (ANA)
b) National League for Nursing (NLN)
c) American Nursing Credentialing Center (ANCC)
d) Sigma Theta Tau International (STTI)
e) American Association of Colleges of Nursing (AACN) -Essentials
f) International Council of Nurses (ICN)
III Components of a HHE defined by key organizations
a) American Psychological Association (APA)
b) World Health Organization (WHO)
c) Institute of Medicine (IOM)
d) Business
e) Robert Wood Johnson Foundation (RWJF)
IV Magnet Hospitals [40]
a) Interdisciplinary health care team
b) Nurses roles on Interdisciplinary health care team
bI Benefits of HHE
a) Quality and safe patient care
b) Collegiality
c) Trusting relationships
d) Professionalism
a) Stress
b) Physical harm
bects of

The effectiveness of this intervention was examined by an- other survey week 8 . At that time, 50 externs completed the survey. Ten externs missed week 8 due to vacation, patientrelated clinical emergencies, or were ill themselves, however all surveys were later emailed to the investigator resulting in a $100 \%$ return rate.

\subsection{Data analysis}

The researcher and two outside reviewers inductively analyzed the survey data inspired by Grounded Theory Approach. By using this approach, we systematically compared and ordered the first survey (week 1) with the second survey responses (week 8) through a constant comparative method, using codes for the relevant thoughts while searching for higher-level themes to organize the codes.

Initially we looked at the first surveys thoroughly and independently constructed themes. We then met and compared our themes which were cogent. Next the researchers analyzed our independent notes from informal discussions that occurred throughout the externship on the clinical units. These discussions added richness to the data. Again, these memos and integrative sessions ${ }^{[41]}$ were similar yet they reflected each extern's individual externship experiences. Comments during the post clinical conference intervention were also considered. The last phase of data analysis considered the final survey results and was completed after the externship.

\subsection{Rigor}

Several procedures were used to ensure reliability and validity. First, the analysis of the data was regularly discussed between the primary investigator and the two outside reviewers to establish credibility and confirmability of the findings. The preliminary themes and code-structure was checked and rechecked to reduce the incidence of bias from the primary investigator. ${ }^{[41]}$ Second, memoing and integrative sessions were used to help make sense of the data with respect to emerging themes. Third, the credibility of the study was established by noting the richness of the data. ${ }^{[41]}$

\section{Findings}

The findings revealed that initially externs had very basic interpretations as to what a HHE means. This most likely is explained by this content being covered in the senior level leadership course which these externs have not had yet. Some externs $(17 \%)$ could not recall if they had the content or not. As noted by the second surveys (week 8), the externs were able to build on their initial thoughts and shared much deeper definitions for HHE, interprofessional teamwork and their role on the team. Findings were 1) increased cognizance of a HHE (88\%); 2) enhanced mindfulness of working in a 
truly collaborative manner with the interprofessional healthcare team to improve decision-making (85\%); 3) recognized how skilled communication among all interprofessional team members leads to a HHE (87\%); and 4) raised awareness of a HHE positively affecting their own health and improved outcomes in their patients $(90 \%)$.

\subsection{Increased cognizance of a HHE}

At the beginning of the externship, externs had very basic understanding of HHEs, their role in maintaining one and how HHEs impacts patient care. They reported things like, "Having a supportive team who helps when needed, both mentally and physically." Another said, "A well timed joke, smile, or a hug can make a world of difference. I think companies focus on physical aspects to ensure safety and prevent injury, but I feel good relationships with co-workers is vital to prevent burn out and protect your mental health."

By the end of the 8 weeks, $88 \%$ of externs reported richer explanations of HHEs, as evidenced by one stating, " $A H H E$ has multiple parts, including working together with one another to accomplish a goal that everyone agrees upon. Communication should be effective between members of the team so goals are met. It includes an actual clean, healthy and safe environment for the employees and patients. These, together help everyone have a good attitude and improves the environment for everyone."

Another extern reported on workload by stating, "if the workload is not manageable, the entire environment is affected and unhealthy for everyone." Another extern stated, "I think a HHE is Respect; Communication; Collaboration; Active Listening; Leadership; Accountability; Optimism; Rewarding/congratulating coworkers on a job well done!"

\subsection{Enhanced mindfulness of working in a truly collabo- rative manner with the interprofessional healthcare team to improve decision-making}

Eighty five percent of externs felt this collaborative awareness to be the most significant area in which they grew. They were witness to how the interprofessional team works on a day-to-day basis and how it impacts the HHE and decisionmaking. Externs gained an understanding of the role of each team member and a clearer appreciation of how they interact.

One extern reported, "Prior to this externship, I read an article about how some departments have hierarchies, and new nurses are left out and "drown before they can swim, this made me nervous. After this externship, I value a place where I feel comfortable asking for help and knowing I can run my thoughts by others. I know I play a role in creating the interprofessional team I want to work on when I graduate."

Published by Sciedu Press
The role of the nursing supervisor became clear to externs. One stated she had "no interaction with a supervisor during her clinical education". Another reported he "sees how a nurse functions collaboratively with members of the team he didn't even know existed ... I now appreciate interdepartmental collaboration, and recognize how supervisors, family and chaplains are all key members and inform my decision-making."

Several externs validated, "as students we are too consumed with our own role, it was nice to appreciate everyone on the team helping each other make decisions. Instead of feeling like if I ask a question-that's a weakness." Many externs admitted as students they were trying to figure out their own role $\mathrm{ON}$ the interprofessional team and were not trying to promote or change anything. Other externs stated, "as a nursing student we are focused on our role and completing care plans, we have very little time to figure out the team idea. We are trying to provide care. This externship helped me to be mindful of the team and how it assists me in making good patient decisions."

\subsection{Recognized how skilled communication among all interprofessional team members leads to a $\mathrm{HHE}$}

The essence of this theme revealed that externs (87\%), had a clearer understanding of skilled communication as defined by the AACN. Externs continued to see themselves as students while in the extern role and consequently, felt they had very little responsibility to communicate in a way to create a HHE. One extern noted, "In promoting a HHE, once I am an RN I will strive to have everyone working together and helping each other succeed by being open and honest. I will be supportive. I can think positive and not put others down or 'bully' them. I will show respect and recognize there is a difference between constructive criticism and bashing a fellow coworker But as an extern, I really can't do much."

Another extern stated that "Just taking time to see if someone needs a hand can be the best thing. If we all communicate openly things run smoothly. A HHE must consist of team members who are open, friendly, and willing to talk. I know that it can be hard to allow students to do things, because we are slow and need guidance, but if nurses communicate respectfully, are patient, and help us then we will become better nurses."

\subsection{Raised awareness of a HHE positively affecting their own health and improved outcomes in their patients}

Most importantly perhaps, this externship helped externs $(90 \%)$ to focus on their internal environment as well as their external environment. These externs were eager to learn and 
were fully engaged when verbalizing how this information would have helped them cope in nursing school and how they plan to implement strategies in their final semester or year of school.

Many acknowledged that a stressed out, anxious approach to caring for patients is not good for them or their patients. One extern stated, "I have to take care of myself. Yes, I heard this before but after working 8 straight weeks, I realize how my stress impacts the entire team. I know to take ownership of myself so I can be an effective team member and my patients have better outcomes." Many externs voiced concern about creating healthy lifestyles so they may be role models to patients.

While many externs conveyed they had not thought about HHEs and their own inner balance, they "now realize that if any environment is not healthy or safe it directly affects them and their patient outcomes." One extern noted, "A HHE is extremely important because the ultimate goal is to make a bad experience into a better experience for patients. During my externship, I am really getting the feel for how I can implement some basic techniques such as deep breathing, staying attentive or just focusing on what I can control to benefit the entire team. I know my patients will also do better."

\section{Discussion}

The basic knowledge expressed by these externs at the outset of the externship highlights the need for HHE content to be included in undergraduate nursing curriculum. Students must recognize the significance of the work environment and its impact on themselves and their wellness and its potential impact on teamwork, communication and effects on safety and patient outcomes. While the concept of work environment was not new to these externs, its impact and implications towards patient care was certainly awakening and reflects an urgent need to address this content earlier in undergraduate curricula and not just in leadership ${ }^{[42]}$ courses.

This study has significant implications for nursing education. First, by recognizing that nursing students are under great amounts of stress, are educated in clinical environments where incivility is rampant and will be graduating into environments where the challenges of the first year will require that they have a repertoire of coping skills on which to rely, we must include this information early on in their education and not just in leadership and senior level courses. Second, academic accrediting bodies must recognize the significance of HHEs and build it into curricular standards for undergraduate education. Third, educators must encourage students to recognize stress, utilize counseling services available through the campus and assist students to initiate personal coping skills. Fourth, nursing education ought to include information with regard to members of the interprofessional health care team, how nurses work as a team and how collaboration fosters healthcare. ${ }^{[22]}$ One way of doing this is allowing students to work as dyads in the clinical learning environment to foster team work and collaborative practice. ${ }^{[11]}$ Students graduating with this awareness will be better equipped to meet the demands of their practice and will be likely to stay. Fifth, raising awareness of HHE begins in the classroom and positively impacts learning. By changing the climate in education, role modelling healthy coping, creating an atmosphere of respect and limiting intimidation, faculty show the importance of respect, collaboration and foster ownership and responsibility for learning. There are many reports ${ }^{[1,37,43]}$ that suggests that by fostering a HHE in undergraduate education the students will then carry them over skills into practice.

\subsection{Strengths and limitations}

This study was the first to ask nursing students to reflect on HHEs and what it means to them. It also was the first study asking nursing externs to recognize their role as a member of the interprofessional healthcare team to identify what they as future healthcare providers can do to create positive healthy teams for themselves as well as to improve patient outcomes.

The study has several limitations. First, externs self-reported their perceived awareness of a HHE and sometimes in a post clinical conference intervention group, which may have been affected by the social desirability phenomenon. ${ }^{[41]}$ Second, externs had different clinical experiences within the externship and consequently experienced a variety of work environments, which could be perceived as a strength or a limitation. Third, student externs came from a variety of academic institutions and were either going into their first semester senior year or second semester senior year which informed their perceptions on the first survey. Fourth, the general overview of externs perceptions regarding HHEs may have been informed by previous jobs and volunteer work. Lastly, these externs had a GPA greater than 3.0 and consequently may have been more motivated to learn about HHEs and interprofessional collaboration.

\subsection{Future research}

Further studies must be carried out to compare how these externs, now equipped with fundamental knowledge regarding a HHE and their role on the interprofessional team compare with other senior nursing students. By comparing outcome measures in nursing school, as well as NCLEX results, and assessing how externs adjust to their first year of practice with students who have not had an extern experience would 
be beneficial. Looking at retention rates and comparing externs with nonexterns would validate the findings of this study. Future research must also address the limitations in this study. A secondary data analysis, comparing some of the demographic variables identified here would also be helpful.

\section{Conclunsions}

This study demonstrates that the participation in a summer nursing externship exposes the student nurses to the work environment and the concept of a HHE as well as the dynamics of the interprofessional team. Externs identified how they might establish and promote a HHE through skilled communication and true collaboration. The externs appreciated learning the role of their interprofessional team members and recognized they need an equal voice on the team to fully be a patient advocate and positively affect patient outcomes.
Externs were not just exposed to HHE for the benefit of the healthcare team but were also able to identify how it is important for them as future nurses.

\section{ACKNOWLEDGeMENTS}

The author would like to thank the externs who have given their time to complete the surveys, the many staff nurses, and nursing faculty who have spent their "summers" mentoring and educating these externs. I would also like to thank the hospital administrators and human resource personnel who are committed to the success of the nursing extern program. In addition, I thank Dr. Charlotte Wool for reviewing this manuscript.

\section{CONFLICTS OF INTEREST Disclosure}

The author declares that there is no conflict of interest.

\section{REFERENCES}

[1] Clark C. Creating and sustaining civility in nursing education. Indianapolis, IN: Sigma Theta Tau International. 2013.

[2] Numminen O, Isoaho H, Meretoja R. Ethical climate and nurse competence-newly graduated nurses' perceptions. Nursing Ethics. 2015; 22(8): 845-859. PMid:25488760 http://dx.doi.org/10. $1177 / 0969733014557137$

[3] Haizlip J, May N, Schorling J, et al. Perspective: The negativity bias, medical education, and the culture of academic medicine: Why culture change is hard. 2012.

[4] Gormley DK. Are we on the same page? Staff nurse and manager perceptions of work environment, quality of care and anticipated nurse turnover. Journal of Nursing Management. 2011; 19: 33-40. PMid:21223403 http://dx.doi.org/10.1111/j.1 365-2834.2010.01163.x

[5] Ulrich BT, Lavendaro R, Woods D, et al. Critical care nurse work environments 2013: A status report. Critical Care Nurse. 2014; 34(4): 64-79. PMid:24811972 http://dx.doi.org/10.4037/ccn2014 731

[6] Ruth-Sahd LA, Beck JA, McCall C. Transformative learning during a summer nursing externship program: The reflections of senior nursing students. Nursing Education Perspectives. 2010; 31(2): 78-83. PMid:20455362

[7] Institute of Medicine. The future of nursing: Leading change, advancing health. Washington DC: National Acadamies Press. 2011. Available from: http://www.nap.edu/catalog/12956/the-f uture-of-nursing-leading-change-advancing-health

[8] Institute of Medicine (IOM). Measuring the impact interprofessional education and collaborative practice and patient outcomes. Washington, DC: The National Academies Press. 2015.

[9] Ramirez YI, Zimmerman R, Judson LH. A student externship program: Academia and service collaboration. Journal of Nursing Regulation. 2013; 4(1): 39-44. http://dx.doi .org/10.1016/S2155 -8256 (15) 30162-9

[10] Rhoads J, Sensenig K, Ruth-Sahd LA, et al. Nursing externship: A collaborative endeavor between nursing education and nursing administration. Dimensions of Critical Care Nursing. 2003; 22: 255-258. http://dx.doi.org/10.1097/00003465-200311000-00008

Published by Sciedu Press
[11] Ruth-Sahd LA. Student nurse dyads create a community of learning: proposing a holistic clinical education theory. Journal of Advanced Nursing. 2011; 67(11): 2445-54. PMid:21615457 http: //dx.doi.org/10.1111/j.1365-2648.2011.05690.x

[12] Remle C, Wittman-Price RA, Derrick T, et al. An 8 week externship program designed for recruitment and retention. Journal for Nurses in Professional Development. 2014; 30(5): E3-7. PMid:25237924 http://dx.doi.org/10.1097/NND. 0000000000000096

[13] Gregory S, Bolling DR, Langston NF. Partnerships and new learning models to create the future perioperative nursing workforce. AORN Journal. 2014; 99(1): 96-105. PMid:24369975 http://dx.doi.o $\mathrm{rg} / 10.1016 / \mathrm{j}$. aorn. 2013.10.012

[14] Souder E, Beverly CJ, Kitch S, et al. Early exposure to geriatric nursing through an externship program. Nursing Education Perspectives. 2012; 33(3): 166-9. PMid:22860479 http://dx.doi.org/10.54 $80 / 1536-5026-33.3 .166$

[15] Lee AY, Ruth-Sahd LA. When the east meets the west: An application of folk medicine in the Amish community. Journal of the Lancaster General Hospital. 2011; 6(4): 114-118.

[16] Browne JA. Healthy workplaces and ethical environments Jeffrey's, M. R. 2012. Nursing student retention: Understanding the process and making a difference (2nd ed.). New York, New York: Springer Publishing Company. 2009.

[17] Cantrell MA, Browne AM. The impact of a nurse extern program of the transition process from graduate to registered nurse. Part III. Recruitment and retention. Journal for Nurses in Staff Development. 2006; 22(1): 11-14. PMid:16465091 http://dx.doi.org/10.10 97/00124645-200601000-00003

[18] Ruth-Sahd LA, Graver SA, Kauffman B. Summer Nursing Externship: Celebrating 15years of Excellence at Lancaster General Hospital. The Journal of the Lancaster General Hospital. 2014; 9(3): 80-84.

[19] Lacher S, DeGeest S, Denhaerynck K, et al. The quality of nurse work environment and workforce outcomes from the perspective of Swiss allied healthcare assistants and registered nurses: A cross sectional survey. Journal of Nursing Scholarship. 2015; 47(5): 458-567. http://dx.doi.org/10.1111/jnu.12151 
[20] Pfaff K, Baxter P, Jack S, et al. An integrative review of the fac tors influencing new graduate nurse engagement in interprofessional collaboration. Journal of Advanced Nursing. 2014; 70(1): 4-20, 27. PMid:23815377 http://dx.doi.org/10.1111/jan.12195

[21] Sullivan M, Kiovsky R, Mason D, et al. Interprofessional collaboration and education. American Journal of Nursing. 2015; 15(3): 47-54. PMid:25715219 http://dx.doi.org/10.1097/01. NAJ . 0000461822.40440 .58

[22] Bender M, Feldman MS. A practice theory to understanding the interdependency of nursing practice and the environment Implications for nurse-led care delivery models Advances in Nursing Science. 2015; 38(2): 96-109. PMid:25932817 http://dx.doi.org/10.1097/A NS. 0000000000000068

[23] Ndoro S. Effective multidisciplinary working: The key to high-quality care. British Journal of Nursing. 2014; 13: 724 727. PMid:25072333 http://dx.doi.org/10.12968/bjon. 201 4.23.13.724

[24] Baker PG. Framework for action on interprofessional education and collaborative practice. World Health Organization Press. 2010.

[25] National League for Nursing. 2006. The healthful work environment toolkit(c). 2013.

[26] Abdou HA, Baddar FM, Alkorashy HA, et al. The relationship between work environment and moral sensitivity among nursing faculty assistants. World Applied Sciences Journal. 2010; 11(11): 13751387.

[27] Brunges M, Foley-Brinza C. Projects for increasing job satisfaction and creating a healthy work environment. AORN Journal. 2014; 100(6): 670-81. PMid:25453685 http://dx.doi.org/10.1016 /j.aorn. 2014.01.029

[28] Clark C. Seeking civility. American Nurse Today. 2014; 9(7): 18-21, 46.

[29] Clark C, Olender L. Fostering civility in nursing education and practice. The Journal of Nursing Administration. 2011; 41(7/8): 324 330. PMid:21799364 http://dx.doi.org/10.1097/NNA.0b013 e31822509c4

[30] Dent RL, Armstead C, Evans B. Three structures for a healthy work environment. AACN Advanced Critical Care. 2014; 25(2): 94 100. PMid:24752020 http://dx.doi.org/10.1097/NCI. 00000 00000000024

[31] Trossman S. Healthy work environment toward civility ANA nurses promote strategies to prevent disruptive behaviors. ANA News. 2014
[32] Ranjbar H. Stress management: An ignored challenge in clinical nursing education. Nurse Education Today. 2016; 36(10). PMid:26602154 http://dx.doi.org/10.1016/j.nedt.2015.10.004

[33] Young LE, Paterson BL. Teaching Nursing: Developing a Studentcentered Learning Environment Lippincott Williams \& Wilkins. 2007.

[34] American Association of Critical Care Nurses. AACN standard for establishing and sustaining health work environment. 2005.

[35] American Organization of Nurse Executives. 2006. Principles \& elements of a healthful practice/work environment. 2013. Available from: http://www.aone.org/aone/PDF/Principlesan dElementsHealthfulEorkPractice.pdf

[36] McNamee M, Attonito KC, Woolforde I. Fostering healthy work environments the through nursing education initiatives. Journal of Continuing Education in Nursing. 2013; 44(5): 199-200. PMid:23656239 http://dx.doi.org/10.3928/00220124-20130424-88

[37] Collins AS, Berry CG, Graves BA, et al. Integrating healthy work environment standards into undergraduate curriculums. AACN Advanced Critical Care. 2009; 20(1): 15-18. PMid:19174632

[38] Maten-Speksnijder A, Grypdonck M, Pool A, et al. Learning to attain an advanced level of professional responsibility. Nurse Education Today. 2015; 35(8): 954-959. PMid:25825354 http://dx.doi.o $\mathrm{rg} / 10.1016 / \mathrm{j}$.nedt .2015.03.005

[39] Hospital and Health System Association of Pennsylvania. A guide to developing extern programs. Harrisburg: HAP Nurse Externship Advisory Committee. Association of American Medical Colleges. 2008; 87(9): 1205.

[40] American Nursing Credentialing Center. Collaboration Tip: Interprofessional Collaboration: Using Stakeholder Mapping to build commitment to quality improvement. 2015. Available from: http://www . nursecredentialing.org/Documents/CKC-D ocs/Consultation/Collaboration-Tip-Interprofession al-Collaboration.pdf

[41] Polit DF, Beck CT. Essentials of nursing research: Appraising evidence for nursing practice. (8th ed.). Philadelphia: Lippincott Williams \& Wilkins. 2014.

[42] Naybeck-Beebe AM, Forsythe T, Funari T, et al. Using evidencebased leadership to create a healthy nursing work environment. Dimension of Critical Care Nursing. 2013; 32(4): 166173. PMid:23759905 http://dx.doi.org/10.1097/DCC.0b013 e3182998121

[43] Brady MS. Healthy nursing academic work environments. Online Journal of Issues in Nursing. 2010; 15(1): 5-15. 